\title{
Status and strategy of marine protected area in Uwedikan Village, Luwuk Timur District, Banggai Regency
}

\author{
Status dan strategi kawasan konservasi perairan daerah di Desa Uwedikan, \\ Kecamatan Luwuk Timur, Kabupaten Banggai \\ Silverius Ariston $^{1 *}$, Unstain N.W.J. Rembet ${ }^{2}$, and Denny B.A. Karwur ${ }^{3}$ \\ ${ }^{1}$ Program Studi Ilmu Perairan, Program Pascasarjana Universitas Sam Ratulangi. Jln. Kampus Unsrat Kleak, \\ Manado 95115, Sulawesi Utara, Indonesia. \\ ${ }^{2}$ Fakultas Perikanan dan Ilmu Kelautan, Universitas Sam Ratulangi. Jl. Kampus Unsrat Bahu, Manado 95115 , \\ Sulawesi Utara, Indonesia. \\ *E-mail: silveriusariston@gmail.co.id
}

\begin{abstract}
Marine Protected Area (MPA) in Uwedikan Village is a conservation area established through Banggai Regent's decree since 2008. The establishment of a marine conservation area does not necessarily solve its management problems. The study aimed to examine the sustainability status of the MPA management of Uwedikan village and to formulate a management strategy. Research method used was a descriptive method through case study approach. Data collection employed questionnaires-based interviews on respondents. The data were analyzed by using Rapid Appraisal for Fisheries Status (Rapfish) to obtain the sustainability status of the MPA in Uwedikan. The Rapfish outcome was then analyzed using Diagnosis and Therapy Analysis of Law (DTAL) to formulate a strategy for the existing management.
\end{abstract}

Keywords: marine protected area; Rapfish; Uwedikan; Banggai.

\begin{abstract}
Abstrak: Kawasan Konservasi Perairan Daerah (KKPD) di Desa Uwedikan merupakan kawasan konservasi yang telah ditetapkan melalui keputusan Bupati Banggai sejak tahun 2008. Penetapan suatu kawasan konservasi laut tidak serta merta dapat menyelesaikan permasalahan pengelolaannya. Penelitian bertujuan untuk mengkaji status keberlanjutan penatakelolaan kawasan konservasi perairan daerah Desa Uwedikan dan merumuskan strategi pengelolaannya. Metode penelitian adalah metode deskriptif melalui pendekatan studi kasus. Pengumpulan data melalui wawancara kuesioner mendalam terhadap responden. Data hasil kuesioner diolah menggunakan analisis yang ada pada Rapid Appraisal for Fisheries Status (Rapfish) sehingga didapatkan status keberlanjutan penatakelolaan KKPD Uwedikan saat ini. Hasil dari Rapfish di analisis menggunakan Diagnosis and Therapy Analysis of Law (DTAL) untuk merumuskan strategi terhadap penatakelolaan yang ada.
\end{abstract}

Kata-kata kunci: kawasan konservasi daerah; Rapfsih; Uwedikan; Banggai.

\section{PENDAHULUAN}

Kawasan Konservasi Perairan Daerah di Desa Uwedikan, awalnya, ditetapkan sebagai Kawasan Konservasi Laut Daerah (KKLD) melalui Keputusan Bupati Banggai No. 523/1209/Dislutkan tahun 2008. Meskipun telah ditetapkan sebagai bagian dari KKPD Kabupaten Banggai, Kawasan Konservasi Perairan Daerah Desa Uwedikan (KKPD Uwedikan) tidak memiliki peraturan daerah ataupun peraturan desa yang mengatur khusus kawasan konservasi ini, sehingga belum ada payung hukum dan sanksi yang jelas untuk mengelola kawasan konservasi ini.

Kegiatan pengelolaan oleh instansi terkait masih terbatas pada pembinaan masyarakat dan penyediaan fasilitas sarana dan prasarana.
Sedangkan kegiatan pengawasan pelaksana utamanya diserahkan ke masyarakat desa melalui kelompok masyarakat pengawas yang telah ditetapkan. Pengawasan yang dilakukan kurang insentif karena masih terbatas pada biaya operasional. Kurangnya pengawasan yang dilakukan mengakibatkan rusak/hilangnya batasbatas zonasi, sehingga saat ini sudah tidak terlihat lagi buih zonasi. Terlebih lagi dengan tidak adanya letak koordinat bagian zonasi, dan luas zonasinya mengakibatkan salah satu masalah pengawasan yang ada di daerah ini. Selain itu, belum ditetapkannya petugas pengelola menjadi dasar utama tidak efektifnya pengawasan yang dilakukan.

Ditetapkannya Undang-Undang 23 tahun 2014, menjadi salah satu polemik utama pemerintah daerah kabupaten/kota dalam mengelola perairan- 
nya. Sebagaimana dalam peraturan tersebut kewenangan daerah perairan dari garis pantai mulai dari 0-12 mil laut sepenuhnya menjadi kewenangan pemerintah daerah provinsi. Hal tersebut berimplikasi terhadap sumber pembiayaan/anggaran pengembangan wilayah laut pada Pemerintah Daerah Kabupaten Banggai.

Rendahnya pendidikan dan pendapatan masyarakat, belum optimalnya kegiatan pengelolaan dan pengawasan, dan beralihnya kewenangan pemerintah daerah kabupaten ke provinsi dalam mengelola perairan laut menjadi dasar permasalahan pengelolaan KKPD di Desa Uwedikan. Oleh sebab itu, untuk meningkatkan pengelolaan yang ada, maka diperlukan kajian melalui pendekatan penatakelolaan untuk mengetahui status dan strategi pengelolaan ke depannya.

\section{MATERIAL DAN METODA}

Penelitian dilakukan di Kawasan Konservasi Perairan Daerah Desa Uwedikan, Kecamatan Luwuk Timur, Kabupaten Banggai, Provinsi Sulawesi Tengah. Pengambilan data dimulai secara bertahap dari unit pengelola, yaitu Dinas Kelautan dan Perikanan, Kabupaten Banggai, instansi terkait, kemudian beralih ke kecamatan dan pedesaan, sampai ke pelaku wisata, LSM, dan Akademisi yang terkait. Metode penelitian adalah metode deskriptif dengan pendekatan studi kasus. Data yang diambil terdiri dari data primer dan data sekunder. Data primer dikumpulkan melalui pembagian kuesioner dan wawancara langsung dari responden untuk mengetahui aspek ekologi,

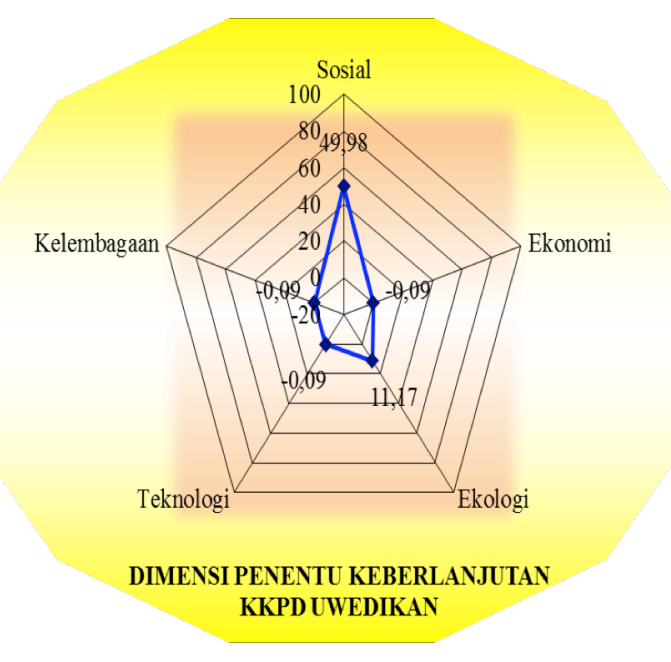

Gambar 1. Dimensi penentu keberlanjutan Kawasan Konservasi Perairan Daerah (KKPD) Uwedikan ekonomi, sosial, teknologi dan kelembagaan, sedangkan data sekunder berasal dari berbagai sumber informasi.

Data yang diperoleh terlebih dahulu diberi nilai peringkat dan diurutkan berdasarkan skoring untuk didapatkan nilai median. Data yang telah diurutkan, kemudian dianalisis menggunakan Rapfish (Rapid Appraisal for Fisheries Status). Analisis ini merupakan salah satu alternatif pendekatan sederhana untuk mengevaluasi status keberlanjutan (Fauzi \& Anna, 2005). Hasil dari Rapfish dianalisis menggunakan DTAL (Diagnosis and Therapy Analysis of Law) sebagai upaya penanggulangan dan penanganan pengelolaan dengan diagnosa dan terapi hukum (Karwur, 2010).

\section{HASIL DAN PEMBAHASAN}

Pada umumnya, penduduk yang tinggal di Desa Uwedikan merupakan penduduk yang sudah menetap lebih dari 5 tahun; dengan mayoritas pekerjaan utamanya adalah nelayan dan beragama Islam. Selain itu, rata-rata penduduk hanya menyelesaikan pendidikan tingkat sekolah dasar dan kebanyakan sudah menikah serta memiliki tanggungan lebih dari 3 orang.

Kondisi Penatakelolaan KKPD Uwedikan saat ini ditentukan melalui hasil ordinasi dari tiap dimensi dengan metode MDS (Multi Dimensional Scalling) dalam Rapfish. Hasil ordinasi rapfish dari dimensi sosial merupakan dimensi dengan nilai ordinasi yang paling tinggi yaitu 49,98 dengan posisi berada ditengah dari titik acuan utama (Reference) dari 'buruk' (bad) ke 'baik' (good) dan berada pada bagian atas $(U p)$. Kondisi ini menunjukkan, bahwa dimensi sosial masuk dalam kategori kurang berkelanjutan sehingga pemanfaatan saat ini cenderung menurun kualitasnya, akan tetapi masih dapat ditingkatkan. Sedangkan, keempat dimensi lainnya memiliki nilai indeks yang sangat kecil sehingga masuk dalam kategori tidak berkelanjutan. Dengan demikian, dimensi sosial merupakan dimensi penentu keberlanjutan penatakelolaan KKPD Uwedikan (Gambar 1).

Berdasarkan pengujian kepastian dan ketepatan atribut Analisis Monte Carlo dalam Rapfish, didapatkan nilai stress 0,13 dan 0,14 dengan nilai $\mathrm{R}^{2}$ sebesar 95\%. Menurut Kavanagh \& Pitcher (2004), nilai stress yang diperbolehkan adalah dibawah nilai $0,25(<0,25)$ dan jika nilai $\mathrm{R}^{2}$ lebih dari $80 \%$ ( $>80 \%$ ) berarti peubah-peubah yang digunakan sudah sangat baik. 


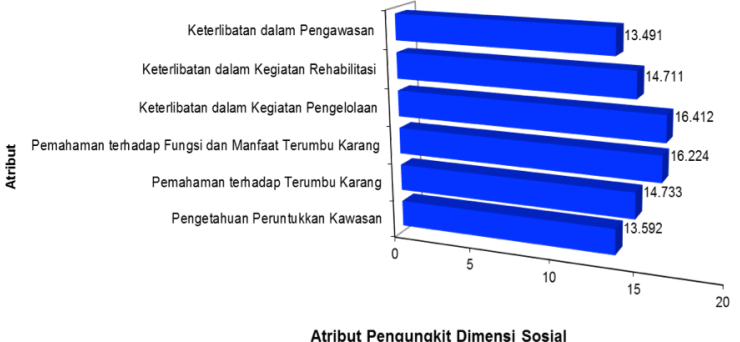

(a)

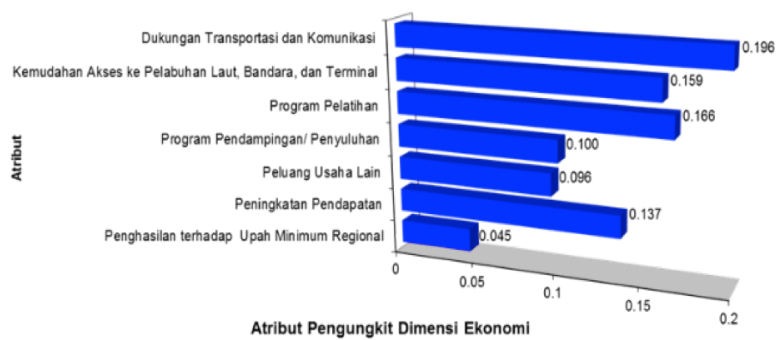

(b)

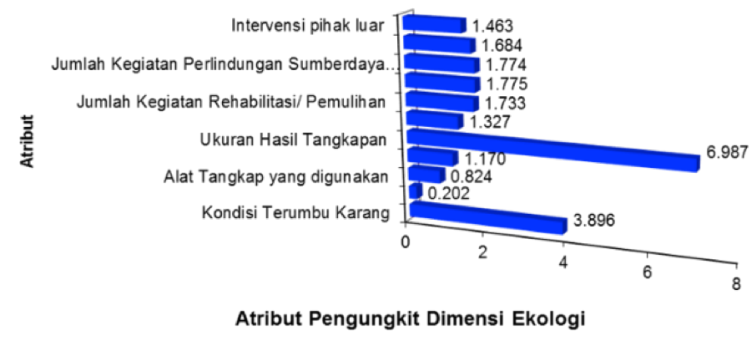

(c)

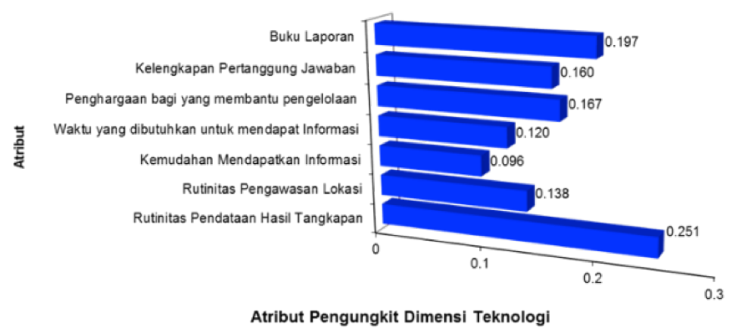

(d)

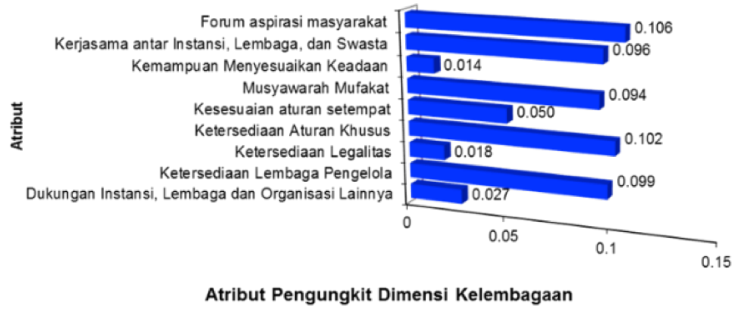

(e)

Gambar 2. Atribut Pengungkit: (a) Dimensi Sosial, (b) Dimensi Ekonomi, (c) Dimensi Ekologi, (d) Dimensi Teknologi, (e) Dimensi Kelembagaan

Hasil analisis atribut pengungkit (leverage attributes) dimensi sosial menunjukkan, bahwa setiap atribut berperan penting dalam pengembangan KKPD Uwedikan. Keterlibatan masyarakat dalam kegiatan pengelolaan dan pemahaman terhadap fungsi dan manfaat terumbu karang menjadi indikator paling penting untuk meningkatkan status keberlanjutan dari dimensi sosial. Pada dimensi ekonomi, yaitu dukungan transportasi dan komunikasi; sedangkan pada dimensi ekologi, ukuran hasil tangkapan dan kondisi terumbu karang merupakan indikator paling penting. Jika dilihat dari dimensi teknologi dan kelembagaan, atribut utamanya, yaitu rutinitas pendataan hasil tangkapan, buku laporan, forum aspirasi masyarakat, ketersediaan aturan khusus, ketersediaan lembaga pengelola, kerjasama antar instansi/lembaga/swasta, dan musyawarah mufakat berperan penting dalam pengembangan KKPD Uwedikan (Gambar 2).

Berdasarkan faktor pengungkit dari kelima dimensi, maka yang menjadi kendala utama penatakelolaan KKPD Uwedikan saat ini, antara lain, adalah: 1) kurangnya pemahaman dan keterlibatan masyarakat; 2) kurangnya dukungan transportasi dan komunikasi; 3) kurangnya pelatihan dan pendampingan yang dilakukan; 4) minimnya ukuran hasil tangkapan; 5) menurunnya kualitas Terumbu Karang; 6) tidak adanya rutinitas pendataan hasil tangkapan; 7) tidak adanya buku pelaporan; 8) tidak adanya forum aspirasi masyarakat; 9) kurangnya musyawarah mufakat; 10) tidak adanya aturan khusus yang mengatur; 11) tidak adanya lembaga pengelola; dan 12) lemahnya kerjasama antar instansi, lembaga dan swasta; 


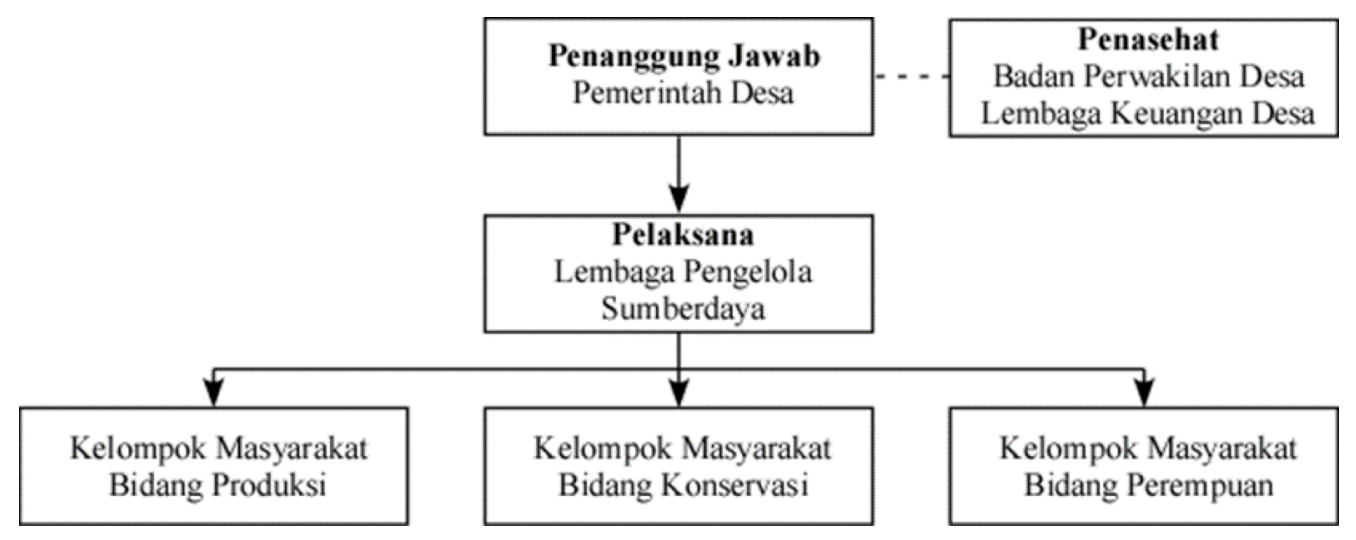

Gambar 3. Contoh Struktur Pengelola DPL-BM

Pemerintah daerah dan desa diharuskan untuk lebih melibatkan masyarakat dalam kegiatan pengelolaan KKPD Uwedikan, untuk menumbuhkan kesadaran dan keaktifan masyarakat dalam menjaga dan merawat lingkungan. Selain itu, pemerintah daerah dan desa perlu mensosialisasikan lebih rinci terhadap fungsi dan manfaat terumbu karang sehingga masyarakat memiliki kesadaran dan pengetahuan dalam pengelolaan kawasan konservasi. Potensi kunjungan wisata akan meningkat, jika tersedianya sarana transportasi dan lancarnya komunikasi ditempat ini. Kebutuhan akan lancarnya sarana transportasi sangat dibutuhkan. Saat ini, untuk mencapai tempat tujuan, harus menggunakan kendaraan pribadi. Akan tetapi, jika menggunakan angkot/taksi lainnya, sangat sulit dan tarif yang diperlukan cukup mahal untuk pengunjung lokal. Apalagi, pada saat akan kembali, sarana transportasi tidak tersedia. Kualitas jaringan seluler yang tersedia saat ini belum mendukung, karena jangkauan signal hanya pada beberapa tempat saja dan tempat lainnya masih belum terjangkau.

Ukuran hasil tangkapan dan kondisi terumbu karang berperan penting dalam pengembangan KKPD Uwedikan. Menurut Charles dalam Bawole, et al. (2011), aktivitas pertumbuhan ikan akan mengalami penurunan jika kebanyakan ikan tertangkap berasal dari jenis yang sedang mengalami pertumbuhan. Oleh karena itu, diperlukan pengaturan terhadap waktu penangkapan dan jumlah yang bisa di tangkap sehingga memberikan kesempatan bagi ikan dan biota lainnya untuk bertumbuh dan berkembang. Selain itu, pengaturan terhadap ukuran ikan yang boleh ditangkap perlu dilakukan melalui pengontrolan terhadap jenis alat tangkap yang digunakan dan lokasi yang diperbolehkan untuk melakukan tangkapan. Pengaturan ini perlu dibuat untuk menghindari terjadinya penangkapan dalam pertumbuhan. Hasil tangkapan harus terdata secara rutin untuk mengetahui siapa saja pelaku yang melakukan tangkapan, alat tangkap yang digunakan, jumlah yang ditangkap, dan ukuran tangkapan. Selain itu, dengan adanya data tangkapan yang jelas, maka informasi potensi dari jenis ikan dan keanekaragaman sumber daya dapat terpantau. Dengan adanya data hasil tangkapan, maka dapat dibuatkan laporan untuk melihat potensi yang ada.

Forum aspirasi masyarakat diperlukan, sebagai tempat yang menampung pendapat, kebutuhan, dan keinginan masyarakat. Setiap keputusan harus berdasarkan masukan dari berbagai aspek jenis masyarakat; untuk itu, maka setiap tindakan harus berdasarkan keputusan bersama yang dimusyawarahkan. Ketersediaan aturan khusus harus dibuat untuk menjadi acuan dalam mengelola dan memberikan sanksi yang jelas sehingga memiliki kekuatan hukum pelaksanaan kegiatan pengelolaan. Selain itu, lembaga pengelola/unit organisasi harus segera dibuat dan ditetapkan untuk menjadi pelaksana perencananaan dan pengawasan KKPD Uwedikan.

Menurut Ilham (2009), skenario pengelolaan KKLD membutuhkan pembentukan lembaga pengelola dengan masyarakat sebagai komponen pengelola di dalamnya, dan tindakan yang tegas dari aparat penegak hukum. Perihal yang sama, ditambahkan oleh Djau (2012), bahwa setiap kebijakan dan strategi pengembangan perikanan harus melibatkan stakeholder, khususnya nelayan, dan perlu adanya kegiatan evaluasi dan monitoring secara berkelanjutan. Selain itu, menurut Salsabiela, et al. (2014), strategi pengelolaan terumbu karang di KKLD memerlukan pengembangan pengelolaan terumbu karang yang ramah lingkungan dengan meningkatkan kesadaran masyarakat, meningkatkan koordinasi masyarakat untuk mengatasi lajunya penurunan degradasi habitat, peningkatan 
kelembagaan demi terwujudnya penegakan hukum, pembuatan dan penegakan aturan.

Berdasarkan UU No. 23 tahun 2014 tentang Pemerintahan Daerah, kewenangan pengelolaan perairan oleh pemerintah daerah kabupaten/kota beralih sepenuhnya menjadi kewenangan pemerintah daerah provinsi. Secara langsung, pembiayaan untuk pengembangan kawasan konservasi perairan daerah tidak bisa lagi dimasukkan dalam APBD kabupaten/kota. Akan tetapi, urusan pemerintahan yang menjadi kewenangan desa dapat dialokasikan ke belanja desa melalui pelimpahan otoritas tugas baik dari pemerintah pusat, provinsi, maupun kabupaten/ kota.

Melalui UU No. 6 tahun 2014 tentang Desa; desa berhak mengatur dan mengurus kepentingan asal usul, adat istiadat, dan nilai sosial budaya masyarakat desa. Desa juga berhak menetapkan dan mengelola kelembagaan desa untuk memenuhi kebutuhan pembangunan seperti kebutuhan primer, pelayanan dasar, lingkungan, dan kegiatan pemberdayaan masyarakat desa. Dengan kata lain, pemerintah desa memiliki kekuatan untuk mengembangkan daerahnya masing-masing. Oleh sebab itu, untuk meningkatkan penatakelolaan KKPD Uwedikan saat ini, maka pemerintah desa dapat membuat peraturan desa dan membentuk lembaga pengelola sehingga KKPD Uwedikan memiliki payung hukum dan komponen pengelola yang jelas.

Menurut COREMAP II and Dirjen KP3K (2006a), peraturan desa (perdes) tentang Daerah Perlindungan Laut Berbasis Masyarakat (DPL-BM) mutlak diperlukan. Keberhasilan pengelolaan suatu kawasan DPL sangat tergantung pada aturan-aturan yang dibuat dan ditetapkan berdasarkan kesepakatan masyarakat. Perdes yang dibuat harus terdiri dari judul, pembukaan, batang tubuh, penutup, penjelasan, dan lampiran. Batang tubuh terdiri ketentuan umum, materi pokok yang diatur (larangan, keharusan, dll), ketentuan dan sanksi. Materi pokok yang diatur meliputi cakupan wilayah, tugas dan tanggung-jawab, kegiatan yang dibolehkan, kegiatan yang dilarang, ketentuan dan sanksi, pendanaan dan pengelolaan dana, pengawasan yaitu pelaku dan metode pengawasan.

Untuk melembagakan pengelolaan sumber daya terumbu karang di tingkat desa, maka harus ditetapkan terlebih dahulu lembaga pengelola sumber daya terumbu karang di desa. Dalam hal ini kelompok masyarakat pengawas (Pokmaswas) Suka Maju (segala usaha kegiatan akan mengancam alam jangan usahakan) dapat dijadikan sebagai lembaga pengelola. Kemudian, lembaga pengelola membentuk kelompok masyarakat bidang produksi, konservasi, dan perempuan. Lembaga pengelola dan pokmas bidangnya sebagai pelaksana, dan pemerintah desa sebagai penanggung jawab. Badan Perwakilan Desa dan Lembaga Keuangan Desa sebagai penasehat. Secara spesifik struktur pengelola dapat mengacu dari Gambar 3 berikut (COREMAP II \& Dirjen KP3K, 2006b).

\section{KESIMPULAN}

Secara umum, didapatkan gambaran mengenai status keberlanjutan penatakelolaan di Kawasan Konservasi Perairan Daerah Desa Uwedikan pada masing-masing dimensi, yaitu dalam kategori buruk atau tidak berkelanjutan. Penatakelolaan KKPD Uwedikan, jika dibiarkan berjalan dalam kondisi saat ini, maka kawasan konservasi ini akan semakin rusak. Strategi penatakelolaan yang dapat dilaksanakan untuk meningkatkan penatakelolaan yang paling utama adalah membuat peraturan desa terhadap pengelolaan KKPD Uwedikan dan membentuk lembaga pengelola sedini mungkin.

\section{REFERENSI}

BAWOLE, R. et al. (2011) Keberlanjutan Penatakelolaan Zona Pemanfaatan Tradisional dalam Kawasan Konservasi Laut Taman Nasional Teluk Cenderawasih Papua Barat. JMHT, 17(2), 71-78.

COREMAP II and Dirjen KP3K. (2006a) Panduan Peraturan Desa tentang Daerah Perlindungan Laut Volume-1. Jakarta: Departemen Kelautan dan Perikanan. 56 p.

COREMAP II and Dirjen KP3K. (2006b) Daerah Perlindungan Laut Berbasis Masyarakat Volume-2. Jakarta: Departemen Kelautan dan Perikanan. $57 \mathrm{p}$.

DJAU, M.S. (2012) Analisis Keberlanjutan Sistem Perikanan di Kawasan Konservasi Laut Daerah (KKLD) Olele dan Perairan Sekitarnya Kabupaten Bone Bolango Provinsi Gorontalo. M.Si. Bogor: Sekolah Pascasarjana Institut Pertanian Bogor. $90 \mathrm{p}$.

FAUZY, A. and ANNA, S. (2005) Pemodelan Sumber Daya Perikanan dan Kelautan. Jakarta: PT Gramedia Pustaka Utama. 343 p.

ILHAM (2009) Kajian Dampak Kawasan Konservasi Laut Daerah terhadap Kondisi Ekologi Terumbu Karang (Studi Kasus Pulau Natuna, Kabupaten Natuna, Provinsi Kepulauan Riau. Tesis. Bogor: Sekolah Pascasarjana Institut Pertanian Bogor. 98 p. 
KARWUR, D.B.A. (2010) Rancangbangun Hukum dalam Pengelolaan Pulau-Pulau Kecil Terluar Kasus Pulau Marore dan Pulau Miangas Provinsi Sulawesi Utara. Disertasi. Bogor: Sekolah Pascasarjana Institut Pertanian Bogor. $92 \mathrm{p}$.

KAVANAGH, P. and PITCHER, T.J. (2004) Implementing Microsoft Excel Software for Rapfish: a Technique for the Rapid Appraisal of Fisheries Status., Fisheries Centre Research, Canada: University of British Columbia, Vol. 12, No. 2.75 p.
SALSABIELA, M., ANGGORO, S. and PURNAWENI, H. (2014) Kajian Keefektifan Pengelolaan Terumbu Karang (Studi Kasus: Kawasan Konservasi Laut Daerah (KKLD) Pulau Biawak dan Sekitarnya, Kabupaten Indramayu. Jurnal Saintek Perikanan, 10(1), 13-18.

Received: 12 February 2018 Accepted: 30 March 2018 